\title{
Double incontinence: associated factors and impact on the quality of life of women attended at a health referral service
}

\author{
Daniel Carvalho Ribeiro 1,2 (D) \\ Júlia Raquel Nunes Souza ${ }^{1}$ (D) \\ Ricardo Antônio Zatti² ${ }^{(D)}$ \\ Thaís Ribeiro Dini ${ }^{\mathbb{1 D}}$ \\ José Rodrigo de Moraes $^{3}$ (DD \\ Carlos Augusto Faria ${ }^{2} \mathbb{D}$
}

\section{Abstract}

Objective: To evaluate the prevalence, associated factors, and impact on quality of life of double incontinence in a group of women with urinary incontinence. Method: A cross-sectional study was performed, including female patients with urinary or double incontinence (urinary and fecal incontinence) treated at a tertiary hospital from the public healthcare system. Information about sociodemographic and clinical characteristics was collected, and quality of life was assessed using validated questionnaires. The MannWhitney, Chi-square, and Fisher tests were used to evaluate the association between the variables and the types of dysfunction (urinary or double incontinence) and a worse general health perception. Results: Of 227 incontinent women included in the study, 120 $(52,9 \%)$ were older individuals. The prevalence of double incontinence was $14.1 \%$ (32 patients). Double incontinence was associated with a higher number of comorbidities $(p$-value $=0.04)$, polypharmacy $(p$-value $=0.04)$, and rectocele $(p$-valor=0.02). Higher BMI $(p$-value $=0.02)$ and number of comorbidities $(p$-value $=0.05)$, but not double incontinence $(p$-value $=0.36)$, were associated with low general health perception scores. Conclusion: the prevalence of double incontinence was different from other studies conducted in similar scenarios. The group of women included in the study presented low general health perception scores, but this was not associated with the presence of double incontinence. A higher number of comorbidities was associated with both double incontinence and a lower general health perception.

\footnotetext{
Centro Universitário Unifaminas, Faculdade de Medicina, Departamento de Anatomia Humana. Muriaé,
MG, Brasil

Centro Universitário Unifaminas, Faculdade de Medicina, Departamento de Anatomia Humana. Muriaé,
MG, Brasil

2 Universidade Federal Fluminense (UFF), Faculdade de Medicina, Departamento Materno-infantil. Niterói, RJ, Brasil

3 Universidade Federal Fluminense (UFF), Instituto de Matemática e Estatística, Departamento de Estatística. Niterói, RJ, Brasil.
} The authors declare there are no conflicts of interest in relation to the present study.

No funding was received in relation to the present study.

Correspondence

Daniel Carvalho Ribeiro

\section{Keywords: Pelvic}

Floor Disorders. Fecal

Incontinence. Urinary

Incontinence. Quality of Life.

Women's Health. 


\section{INTRODUCTION}

Due to the female pelvic anatomy, which not only allows the elimination of urinary and gastointestinal tracts products but also enables parturition, women are more susceptible to pelvic floor dysfunctions (PFDs), which include anal and fecal incontinence, genital prolapse and urinary incontinence ${ }^{1,2}$. These can occur separately or in combination in the same patient ${ }^{3}$. PFDs have an important negative impact on quality of life (QoL) and, in certain cases, cause greater impairment of the QoL than chronic diseases, such as heart failure and chronic obstructive pulmonary disease ${ }^{4}$.

According to the standard nomenclature of the International Continence Society (ICS) and the International Urogynecological Association (IUGA), urinary incontinence (UI) is defined as the complaint of any involuntary loss of urine ${ }^{5}$. Its cause is multifactorial, with age, number of deliveries, vaginal deliveries, obesity, being postmenopausal and undergoing gynecological surgery the main risk factors. Anal incontinence (AI) corresponds to the involuntary loss of feces or flatus, while fecal incontinence $(\mathrm{FI})$ is the involuntary loss of solid and/or liquid stools ${ }^{6}$. The main risk factors for AI are age, vaginal deliveries, obesity, genital prolapse, diarrhea and trauma to the anal sphincter?

With changes in life expectation and lifestyle, other risk factors for PFDs have emerged. The combination of several chronic diseases and the multiple medications used to treat them may be involved in mechanisms that lead to urinary and fecal incontinence ${ }^{8}$.

As they have the same pathophysiology and share risk factors, the combination of UI and FI, known as double incontinence (DI), is not uncommon, and is considered the most severe and debilitating manifestation of female pelvic floor dysfunction.

A population-based study carried out among American women aged over 62 years old found a prevalence of DI of $7 \%$. Studies in Brazilian populations have found a prevalence of $2 \%$ in women over 20 years old ${ }^{10}$, and $4.9 \%$ in those over 65 years old ${ }^{11}$.
DI severely affects QoL ${ }^{2,12}$. Women who suffer this condition avoid leaving home, must constantly use geriatric napkins or diapers and are concerned about exhaling urine and/or feces odors, which also affects their sex life. All of these conditions are associated with low self-esteem and impaired mental health ${ }^{13}$.

The impact of PFDs on QoL can be assessed through questionnaires developed specifically for this purpose, translated and validated in several languages. These include the King's Health Questionnaire $(\mathrm{KHQ})^{14}$, for UI, and the Fecal Incontinence Quality of Life Scale (FIQL) ${ }^{15}$, both translated and validated for Brazilian Portuguese.

The existence of myths and beliefs, which lead women to believe that pelvic floor dysfunctions are a natural consequence of processes such as pregnancy and aging, coupled with patients' feeling of shame and embarrassment, often prevent them from seeking help. On the other hand, health professionals are not always trained to investigate the symptoms of $\mathrm{PFD}^{16}$.

The Brazilian population, which is mostly made up of women, has undergone a rapid aging process, and these two conditions are associated with a higher prevalence of PFD. Therefore, the present study aimed to assess the prevalence of DI in a specialized outpatient clinic and to identify sociodemographic factors, past pathological history, gynecological obstetric history, and gynecological examination findings associated with DI in comparison to UI alone. In addition, the present study aimed to identify the impact of DI on self-perceived health, controlling for sociodemographic factors, past pathological history, gynecological obstetric history and gynecological examination, and to assess the impact of FI on QoL.

\section{METHODS}

A cross-sectional, retrospective study was carried out using the database of the Urogynecology outpatient clinic of Hospital Universitário Antônio Pedro, in Niterói (Rio de Janeiro, Brazil), from April 2010 to December 2016. 
Patients from the municipal districts of the Metropolitan Region II of the state of Rio de Janeiro, composed of the Niterói, São Gonçalo, Maricá, Itaboraí, Rio Bonito, Silva Jardim and Tanguá districts, referred by the Unified Health System (SUS) network due to complaints of urinary incontinence, were evaluated at the gynecology outpatient clinic and referred for urogynecological evaluation.

The sample is therefore convenience based, in which the data included were of female patients, aged 18 years or older, who had maintained their cognitive capacity, had a clinical complaint of urinary incontinence, with or without fecal incontinence. Cases where there was a history of bowel cancer, a prior colostomy or inflammatory bowel diseases were excluded.

The diagnosis of urinary and fecal incontinences was established through the symptoms referred to during anamnesis, and the combination of the two was considered double incontinence.

The following sociodemographic, clinical history and physical examination information was collected: age, education, mode of deliveries, history of surgery for prolapse and hysterectomy, number of comorbidities, number of medications in use, history of constipation, body mass index diagnosis and diagnosis of genital prolapse according to the Pelvic Organ Prolapse Quantification system (POP-Q) ${ }^{17}$.

The number of comorbidities variable was divided into three categories (none, one and two or more). Polypharmacy was considered to be the simultaneous use of five or more medications ${ }^{18}$.

According to the BMI, the women were classified as normal weight (BMI values from 18.5 to $24.9 \mathrm{~kg}$ / $\mathrm{m}^{2}$ ), overweight (values from 25 to $29.9 \mathrm{~kg} / \mathrm{m}^{2}$ ) or obese (index greater or equal to $30 \mathrm{~kg} / \mathrm{m}^{2}$ ). Women aged 60 years or above were considered older.

All patients had urinary incontinence and, therefore, responded to the KHQ questionnaire to estimate the specific impact of this condition on their quality of life on the first visit ${ }^{14}$. Patients with double incontinence (urinary and fecal) answered the Fecal Incontinence Quality of Life (FIQL) questionnaire on their return visit ${ }^{15}$.
The King's Health Questionnaire (KHQ) assesses general health and the impact of urinary incontinence on daily, physical and social activities, in addition to the impairment of personal relationships, sleep and mood, and measures the severity of urinary incontinence. The higher the score calculated from the patient's responses, the worse the QoL. It was validated for Portuguese in $2003^{14}$.

The FIQL was validated for Portuguese in 2004. It has four domains: lifestyle, behavior, depression and embarrassment. For this questionnaire, the lower the score calculated from the patient's answers, the worse the $\mathrm{QoL}^{15}$.

The answers to the first KHQ question How would you describe your bealth at the moment? refer to the self-assessment of the general perception of health, and include the responses very good, good, fair, poor and very poor. It was considered that patients who chose the first two options had a better perception of health, while the others had a worse perception, and these two groups were therefore used for analysis. Although this option is controversial, it is the most commonly used in literature ${ }^{19}$.

Initially, a descriptive or exploratory analysis was carried out for all the variables considered in the study. For the quantitative variables, including the FIQL domain scores, position and variability measures were calculated, while for qualitative variables, absolute (number of cases) and relative (percentage of cases) distributions were constructed.

To establish the association between the categorical variables (education, mode of delivery, history of gynecological surgeries (hysterectomy and perineoplasty), comorbidities, polypharmacy, constipation and stage of genital prolapse) and the types of dysfunction (urinary incontinence and double incontinence) and also with a worse general perception of health, the Chi-square and Fisher tests were used, where applicable. For the numerical variables, the Mann-Whitney test was used.

When assessing the significance of the effects of the variables on the outcome of the study, a level of significance of 5\% was applied. 
The study complied with resolutions no. 466/2012 and 510/2016, and was approved by the HUAP/UFF Ethics and Research Committee (approval number 51112315.2.0000.5243).

\section{RESULTS}

The study sample consisted of 227 women with a mean age of $60.07 \pm 11.10$ (30-86 years) years and an average BMI of $29.63 \pm 5.84(14.60-46.15 \mathrm{~kg} /$ $\left.\mathrm{m}^{2}\right)$. Of these, $120(52.9 \%)$ were considered older women. Regarding the mode of delivery, most patients $(38.8 \%)$ had experienced both a vaginal and cesarean delivery. A total of 132 (58.1\%) patients had two or more comorbidities, while 58 (25.6\%) used more than four medications.

The prevalence of double incontinence in the sample was $14.1 \%$ (Table 1).

Regarding the quality of life domain "general health perception" of the KHQ questionnaire, 198 women had scores greater than or equal to 50 , that is, fair, poor or very poor QoL (Table 2).

BMI and number of comorbidities exhibited a statistically significant association with a worse general health perception (scores $\geq 50$ ), but there was no difference between women with only UI and those with double incontinence (Table 2).

Regarding type of dysfunction, polypharmacy, the presence of two or more comorbidities and posterior vaginal wall prolapse showed a statistically significant association with the presence of double incontinence (Table 3).

Among the patients with FI, 12 did not answer the FIQL questionnaire, due to reasons such as missing the return visit and refusal, as they considered answering the questionnaire tiring. Of the remaining 20 women, low mean QoL scores were observed in all domains, with the embarrassment domain being the most affected. When considering the median, the embarrassment and behavior domains were the most impaired (Table 4). 
Table 1. Sociodemographic and clinical profile of 227 women with urinary or double incontinence attended at the urogynecology outpatient clinic of the Hospital Universitário Antônio Pedro, Niterói (Rio de Janeiro), 2016.

\begin{tabular}{|c|c|}
\hline Variables & $\begin{array}{l}\text { Percentage of patients }(\mathrm{N}=227) \\
\mathrm{n}(\%)\end{array}$ \\
\hline \multicolumn{2}{|l|}{ Dysfunction group } \\
\hline Double incontinence (UI and FI) & $32(14.1 \%)$ \\
\hline UI only & $195(85.9 \%)$ \\
\hline \multicolumn{2}{|l|}{ Education } \\
\hline Up to and including primary & $168(74 \%)$ \\
\hline Secondary or higher & $59(26 \%)$ \\
\hline \multicolumn{2}{|l|}{ Mode of delivery } \\
\hline Normal & $85(37.4 \%)$ \\
\hline Cesarean & $42(18.5 \%)$ \\
\hline Both & $88(38.8 \%)$ \\
\hline No delivery & $12(5.3 \%)$ \\
\hline \multicolumn{2}{|l|}{ Diabetes } \\
\hline Yes & $56(24.7 \%)$ \\
\hline No & $171(75.3 \%)$ \\
\hline \multicolumn{2}{|l|}{ No. of comorbidities } \\
\hline None & $33(14.5 \%)$ \\
\hline One & $62(27.3 \%)$ \\
\hline Two or more & $132(58.1 \%)$ \\
\hline \multicolumn{2}{|l|}{ Polypharmacy } \\
\hline Yes & $58(25.6 \%)$ \\
\hline No & $169(74.4 \%)$ \\
\hline \multicolumn{2}{|l|}{ Constipation } \\
\hline Yes & $59(26 \%)$ \\
\hline No & $168(74 \%)$ \\
\hline \multicolumn{2}{|l|}{ Abdominal hysterectomy } \\
\hline Yes & $50(22 \%)$ \\
\hline No & $177(78 \%)$ \\
\hline \multicolumn{2}{|l|}{ Colpoperineoplasty } \\
\hline Yes & $49(21.6 \%)$ \\
\hline No & $178(78.4 \%)$ \\
\hline \multicolumn{2}{|l|}{ Anterior prolapse } \\
\hline Yes & $135(59.5 \%)$ \\
\hline No & $92(40.5 \%)$ \\
\hline \multicolumn{2}{|l|}{ Posterior prolapse } \\
\hline Yes & $85(37.4 \%)$ \\
\hline No & $142(62.6 \%)$ \\
\hline \multicolumn{2}{|l|}{ Apical prolapse } \\
\hline Yes & $37(16.3 \%)$ \\
\hline No & $190(83.7 \%)$ \\
\hline
\end{tabular}

UI=Urinary Incontinence; FI=Fecal Incontinence.

Source: Authors. 
Table 2. Association between sociodemographic and clinical variables and the general health perception of 227 women attended at the urogynecology outpatient clinic of the Hospital Universitário Antônio Pedro, Niterói (Rio de Janeiro), 2016.

\begin{tabular}{|c|c|c|c|}
\hline \multirow[b]{2}{*}{ Variables } & \multicolumn{2}{|c|}{ General Perception of Health (PGS) } & \multirow[b]{2}{*}{ p-value } \\
\hline & $\begin{array}{l}\text { Good }(\mathrm{N}=29) \\
\mathrm{n}(\%)\end{array}$ & $\begin{array}{l}\text { Poor }(\mathrm{N}=198) \\
\mathrm{n}(\%)\end{array}$ & \\
\hline \multicolumn{4}{|l|}{ Dysfunction group * } \\
\hline Double incontinence (UI, FI) & $2(6.2)$ & $30(93.8)$ & \multirow{2}{*}{0.36} \\
\hline UI only & $27(13.9)$ & $168(86.1)$ & \\
\hline Age (in years) $* *$ & $61.8 \pm 10.7$ & $59.8 \pm 11.2$ & 0.33 \\
\hline BMI (in $\mathrm{kg} / \mathrm{m} 2$ ) $* *$ & $27.3 \pm 4.6$ & $30.0 \pm 5.9$ & 0.02 \\
\hline \multicolumn{4}{|l|}{ Education } \\
\hline Up to and including primary & $19(11.3)$ & $149(88.7)$ & 0.26 \\
\hline Secondary or higher & $10(17)$ & $49(83.1)$ & \\
\hline \multicolumn{4}{|l|}{ Type of delivery } \\
\hline Normal & $13(15.3)$ & $72(84.7)$ & 0.09 \\
\hline Cesarean & $1(2.4)$ & $41(97.6)$ & \\
\hline Both & $13(14.7)$ & $75(85.3)$ & \\
\hline No delivery & $2(16.7)$ & $10(83.3)$ & \\
\hline \multicolumn{4}{|l|}{ Diabetes Mellitus } \\
\hline Yes & $4(7.1)$ & $52(92.9)$ & 0.15 \\
\hline No & $25(14.6)$ & $146(85.4)$ & \\
\hline \multicolumn{4}{|l|}{ No. of comorbidities } \\
\hline None & $10(18.2)$ & $46(81.8)$ & 0.05 \\
\hline One & $15(15.8)$ & $80(84.2)$ & \\
\hline Two or more & $4(9.8)$ & $72(90.2)$ & \\
\hline \multicolumn{4}{|l|}{ Polypharmacy } \\
\hline Yes & $5(8.6)$ & $53(91.4)$ & 0.27 \\
\hline No & $24(14.2)$ & $145(85.8)$ & \\
\hline \multicolumn{4}{|l|}{ Constipation } \\
\hline Yes & $8(13.6)$ & $51(86.4)$ & 0.83 \\
\hline No & $21(12.5)$ & $148(87.5)$ & \\
\hline \multicolumn{4}{|l|}{ Abdominal hysterectomy } \\
\hline Yes & $3(6)$ & $47(94)$ & 0.10 \\
\hline No & $26(14.7)$ & $151(85.3)$ & \\
\hline \multicolumn{4}{|l|}{ Colpoperineoplasty } \\
\hline Yes & $4(8.2)$ & $45(91.8)$ & 0.27 \\
\hline No & $25(14.0)$ & $153(86)$ & \\
\hline \multicolumn{4}{|l|}{ Anterior prolapse } \\
\hline No & $8(8.7)$ & $84(91.3)$ & 0.13 \\
\hline Yes & $21(15.6)$ & $114(84.4)$ & \\
\hline \multicolumn{4}{|l|}{ Posterior Prolapse } \\
\hline No & $15(10.6)$ & $127(89.4)$ & 0.20 \\
\hline Yes & $14(16.5)$ & $71(83.5)$ & \\
\hline \multicolumn{4}{|l|}{ Apical Prolapse } \\
\hline No & 21(11.1) & $169(88.9)$ & 0.08 \\
\hline Yes & $8(21.6)$ & $29(78.4)$ & \\
\hline
\end{tabular}

UI=Urinary Incontinence; FI=Fecal Incontinence; ${ }^{*}$ Fisher's Exact Test (bilateral); ${ }^{*}$ Mann-Whitney Non-Parametric Test (bilateral); other analyses $=$ Chi-square $($ bilateral $) ; p \leq 0.05$.

Source: Authors. 
Table 3. Association between sociodemographic and clinical variables and the dysfunction group of 227 women attended at the urogynecology outpatient clinic of the Hospital Universitário Antônio Pedro, Niterói (Rio de Janeiro), 2016.

\begin{tabular}{|c|c|c|c|}
\hline \multirow[b]{2}{*}{ Variables } & \multicolumn{2}{|c|}{ Dysfunction } & \multirow[b]{2}{*}{ p value } \\
\hline & $\begin{array}{l}\mathrm{UI} \text { and FI }(\mathrm{n}=32) \\
\mathrm{n}(\%)\end{array}$ & $\begin{array}{l}\text { UI Only }(\mathrm{n}=195) \\
\mathrm{n}(\%)\end{array}$ & \\
\hline Age (in years) $*$ & $60.1 \pm 10.5$ & $60.1 \pm 11.2$ & 0.93 \\
\hline $\mathrm{BMI}(\text { in } \mathrm{kg} / \mathrm{m} 2)^{*}$ & $28.6 \pm 5.90$ & $29.7 \pm 5.8$ & 0.32 \\
\hline \multicolumn{4}{|l|}{ Education } \\
\hline Up to primary & $26(15.5)$ & $142(84.5)$ & 0.31 \\
\hline Secondary or higher & $6(10.2)$ & $53(89.8)$ & \\
\hline \multicolumn{4}{|l|}{ Mode of delivery $* *$} \\
\hline Normal & $11(12.9)$ & 74 (87.1) & 0.41 \\
\hline Cesarean & $4(9.5)$ & $38(90.5)$ & \\
\hline Both & $16(18.1)$ & $72(81.9)$ & \\
\hline No delivery & $1(8.3)$ & $11(91.7)$ & \\
\hline \multicolumn{4}{|l|}{ Diabetes Mellitus } \\
\hline Yes & $11(19.6)$ & $45(80.4)$ & 0.17 \\
\hline No & $21(12.3)$ & $150(87.7)$ & \\
\hline \multicolumn{4}{|l|}{ No. of comorbidities } \\
\hline None & $4(7.2)$ & $52(92.8)$ & 0.04 \\
\hline An & 11 (11.6) & $84(88.4)$ & \\
\hline Two or more & $17(22.4)$ & $59(77.6)$ & \\
\hline \multicolumn{4}{|l|}{ Polypharmacy } \\
\hline Yes & $13(22.4)$ & 45 (77.6) & 0.04 \\
\hline No & $19(11.2)$ & $150(88.8)$ & \\
\hline \multicolumn{4}{|l|}{ Constipation } \\
\hline Yes & $8(13.6)$ & $51(86.4)$ & 0.89 \\
\hline No & $24(14.2)$ & $144(85.8)$ & \\
\hline \multicolumn{4}{|c|}{ Abdominal hysterectomy } \\
\hline Yes & $8(16)$ & $42(84)$ & 0.66 \\
\hline No & $24(13.56)$ & $153(86.44)$ & \\
\hline \multicolumn{4}{|l|}{ Colpoperineoplasty } \\
\hline Yes & $6(12.2)$ & $43(87.8)$ & 0.67 \\
\hline No & $26(14.6)$ & $152(85.4)$ & \\
\hline \multicolumn{4}{|l|}{ Anterior prolapse } \\
\hline No & $10(10.9)$ & $82(89.1)$ & 0.25 \\
\hline Yes & $22(16.3)$ & $113(83.7)$ & \\
\hline \multicolumn{4}{|l|}{ Posterior Prolapse } \\
\hline No & $14(9.9)$ & $128(90.1)$ & 0.02 \\
\hline Yes & $18(21.2)$ & $67(78.8)$ & \\
\hline \multicolumn{4}{|l|}{ Apical Prolapse } \\
\hline No & $30(14.8)$ & $173(85.2)$ & 0.39 \\
\hline Yes & $2(8.3)$ & $22(91.7)$ & \\
\hline
\end{tabular}

UI=Urinary Incontinence ;FI= Fecal Incontinence; *Mann-Whitney Non-Parametric Test (bilateral); ${ }^{* *}$ Fisher's Exact Test (bilateral); other analyses $=$ Chi-square (bilateral); ${ }^{*} p \leq 0.05$.

Source: Authors. 
Table 4. Impact of symptoms of Fecal Incontinence on quality of life according to Fecal Incontinence Quality of Life (FIQL) questionnaire in 20 women with Fecal Incontinence attended at the outpatient clinic of the Hospital Universitário Antônio Pedro, Niterói (Rio de Janeiro), 2016.

\begin{tabular}{lll}
\hline Domain & Mean $\pm \mathrm{sd}$ & Median (AI) \\
\hline Embarrassment & $1.67 \pm 0.96$ & $1.50(1.33)$ \\
Behavior & $1.69 \pm 0.89$ & $1.31(1.50)$ \\
\hline Lifestyle & $2.19 \pm 1.05$ & $2.30(1.78)$ \\
\hline Depression & $2.28 \pm 0.99$ & $2.36(1.79)$ \\
\hline
\end{tabular}

$\mathrm{sd}=$ standard-deviation; $\mathrm{AI}=$ interquartile range.

Source: Authors.

\section{DISCUSSION}

The sample of the female population with urinary incontinence, combined or not with fecal incontinence, included in this study was characterized as being over sixty years old and overweight, as well as having at least one comorbidity and using several medications. Double incontinence, present in $14.1 \%$ of cases, was associated with a greater number of comorbidities, polypharmacy and a diagnosis of rectocele. Most women $(87.2 \%)$ had a negative perception of their health, which was associated with a higher BMI and the presence of a greater number of comorbidities, but not with the presence of double incontinence.

The prevalence of fecal incontinence (14.1\%) should be assessed in the context of the population studied, who had at least one pelvic floor dysfunction, UI, and therefore represent a specific group that differs from the general population. The same consideration applies to the analysis of the associated factors and the general perception of health.

The prevalence rates of double incontinence in the overall Brazilian population vary between 2 and $18.1 \%{ }^{10,11,20}$, whereas in the USA they vary between 6 and $7 \% \%^{9,21}$. Studies carried out in populations with urinary incontinence treated at specialized services are more closely related to the sample of the present study, and prevalence rates of 5.5\% in Turkey ${ }^{22}, 8 \%$ in Thailand ${ }^{23}, 18 \%$ in the USA ${ }^{24}$, and $40.5 \%$ in Brazil have been identified ${ }^{25}$.

Such disparity in relation to the findings of the present study may be due to the genetic and pelvic floor make up of each population (predominantly white, among North American women, of flatus miscegenated, in Brazil, and Thai or Turkish in Asia), as well as cultural differences between Western and Eastern populations regarding the embarrassment of describing symptoms and how to deal with them. Another factor that may explain the difference are the different definitions used by the authors, as the Brazilian and Thai studies investigated the diagnosis of anal incontinence, and it is possible that patients with only flatal incontinence, which is more common, were included among those with double incontinence. ${ }^{22,25}$

With regard to self-perceived health, the fact that all the women also have UI, which represents not only hygienic discomfort, but also results in social, sexual, psychological and economic problems, may justify the high proportion of women with a negative perception of health. According to Reigota et al. ${ }^{26}, 64.1 \%$ of a sample of 325 incontinent Brazilian women aged 50 and over also classified their health as fair, poor or very poor.

There was no association between DI and a worse general health perception, in comparison with women with only UI. Similarly, there was no difference in the scores of the general perception of health assessed using the SF-36 between Brazilian women with only AI, with AI and prolapse, and with double incontinence ${ }^{27}$. In the USA, worse health-related QoL scores were observed in women with FI and urinary incontinence, when compared with women who presented only urge urinary incontinence ${ }^{26}$. These patients were younger, and most likely had greater demands in relation to labor activity, social relationships and sex life, and the presence of FI may have constituted an additional factor for impaired QOL. 
In contrast, the factors that were associated with a worse general health perception in the population of women with UI studied were BMI and number of comorbidities.

The prevalence of obesity and overweight individuals has reached epidemic proportions worldwide, and women in the menopausal transition and post-menopause periods - such as the population included in the present study - are more susceptible to this ${ }^{27}$. Among obese women there is a record of lower quality of life scores ${ }^{28}$. Obesity is also associated with other comorbidities, such as hypertension, coronary disease, diabetes and metabolic syndrome, among others, and the number of comorbidities is associated with a worse quality of life. This impact is more pronounced in the female population ${ }^{28,29}$. It is worth mentioning that the risk of UI, another factor associated with worse QoL, increases as BMI increases ${ }^{30,31}$.

Studies on the factors associated with DI in different population scenarios reveal contrasting results, which can be explained by the different characteristics of the individuals included, in relation to age, nutritional status, parturition, presence of comorbidities and genital prolapse. In addition, populations from different regions of the world have different genetic loads, which influences the resistance of the tissues that make up the female pelvic floor. It should also be considered that the authors of each study choose to include certain variables that they consider most plausibly associated with DI, and these variables often do not coincide among researchers.

Camtosun et al. ${ }^{22}$, in Turkey found no association between stage 2 and 3 rectocele and DI, which is at odds with the findings of the present study. On the other hand, among the variables studied that are common to the present study, there was also no association between DI and age, BMI, type of delivery, hysterectomy or diabetes.

Markland et al. ${ }^{24}$, meanwhile, in a similar manner to the analyses of the present study, observed an association between posterior wall prolapse and DI, and found no association with education, diabetes and hysterectomy, among other variables. In contrast, however, an association was found between BMI and number of normal births with DI.

According to Wu et al. ${ }^{21}$, double incontinence in women was associated with non-Hispanic, white ethnicity, depression, more than three comorbidities, hysterectomy and diarrhea. For Yuaso et al. ${ }^{11}$, in a Brazilian population, the factors associated with double incontinence were the presence of hypertension, polypharmacy and falls in the previous year. Both studies did not include the presence of genital prolapse among the studied variables.

In American women with UI, FI and genital prolapse alone or in combination, Andy et al. ${ }^{32}$ found no association between posterior prolapse and symptoms of FI. However, it was observed that FI was associated with polypharmacy, which may be due to the presence of several comorbidities. Matthews et al. ${ }^{9}$ found that comorbidities, in addition to depression and multiparity, were more associated with DI than with UI or FI in isolation.

Prolapse of the posterior wall, or rectocele, especially in its more advanced stages, is associated with neuromuscular and functional defects, which lead to a variety of symptoms ranging from obstructed defecation to fecal incontinence ${ }^{33}$.

The present study was carried out in a tertiary hospital of the Brazilian National Health Service, or SUS, whose clientele frequently presents multiple comorbidities and makes use of several medications simultaneously, representing polypharmacy ${ }^{18}$. Such characteristics are also found in the scope of SUS primary care ${ }^{18}$. The greater the number of drugs used, the greater the risk of drug interactions and adverse effects. Various medications can have effects on the gastrointestinal tract, either leading to diarrhea, such as metformin, or constipation (opioids, antidepressants, anticholinergics), both related to the presence of FI in literature ${ }^{34,35}$.

There was no association between constipation and double incontinence, in contrast to the study by Andy et al.32, who observed greater severity of fecal incontinence when related to constipation, and the study by Camtosun et al. ${ }^{22}$. 
In the present study, information on the presence of constipation was obtained through anamnesis, without using a specific instrument, which differs from the study by Andy et al. ${ }^{32}$, who used a validated questionnaire, and this may have influenced the result. On the other hand, although the findings of Camtosun et al. ${ }^{22}$ were also based on medical history, the population was younger, included patients with fecal and/or flatal incontinence in the same group and found a lower prevalence of these symptoms when compared with the present study, which may explain the differences in results.

Regarding the assessment of the impact of FI on QoL through the FIQL questionnaire, lower scores were observed for the domains of embarrassment and behavior. Such a result is similar to that of Portella et al. ${ }^{25}$.

Although they studied populations with DI, the studies by Camtuson et al. ${ }^{22}$ and Markland et al. ${ }^{24}$ did not use specific questionnaires to assess the impact of FI on QoL. They observed, however, that women with DI have worse scores in the questionnaires to assess the specific impact of UI on QoL, than women with only UI.

The limitations of the present study are its selection bias, as it was carried out in a tertiary health unit, the use of convenience sampling, involving mainly more severe cases, and the loss of patients with regard to the completion of the FIQL questionnaire. Its strengths, however, relate to the novelty of the environment, as there are few studies on prevalence and factors associated with DI in the Brazilian population, the use of a specific instrument, validated for the Portuguese language spoken in Brazil, to measure the impact of FI on quality of life, as well as the assessment of genital prolapse through the POP-Q system, and not simply clinical complaints relating to such dysfunction.

\section{CONCLUSIONS}

In the studied population, the prevalence of double incontinence was $14.1 \%$, lower than that observed in studies carried out in similar scenarios.

The factors associated with double incontinence were a higher number of comorbidities, polypharmacy and the presence of rectocele.

The general health perception was negative for $87.2 \%$ of the patients. An elevated BMI and a greater number of comorbidities were associated with a worse general perception of health. There was no association between double incontinence and a worse general health perception.

Quality of life was impaired in all the domains of the FIQL questionnaire, with the lowest scores observed for the domains of embarrassment and behavior.

Edited by: Ana Carolina Lima Cavaletti

\section{REFERENCES}

1. Hallock JL, Handa VL. The Epidemiology of pelvic floor disorders and childbirth: an update. Obstet Gynecol Clin North Am. 2016;43(1):1-13.

2. Freeman A, Menees S. Fecal incontinence and pelvic floor dysfunction in women: a review. Gastroenterol Clin North Am. 2016;45(2):217-37.

3. Lawrence JM, Lukacz ES, Nager CW, Hsu JWY, Luber KM. Prevalence and co-occurrence of pelvic floor disorders in community-dwelling women. Obstet Gynecol. 2008;111(3):678-85.
4. Cheung RY, Chan S, Yiu AK, Lee LL, Chung TK. Quality of life in women with urinary incontinence is impaired and comparable to women with chronic disease. Hong Kong Med J. 2012;18(3):214-20.

5. Haylen BT, De Ridder D, Freeman RM, Swift SE, Berghmans B, Lee J, et al. An International Urogynecological Association (IUGA)/International Continence Society (ICS) joint report on the terminology for pelvic floor dysfunction. Int Urogynecol J. 2010;21(1):5-26. 
6. Sultan AH, Monga A, Lee J, Emmanuel A, Norton C, Santoro G, et al. An International Urogynecological Association (IUGA)/International Continence Society (ICS) joint report on the terminology for female anorectal dysfunction. Int Urogynecol J. 2017;28(1):5-31.

7. Bharucha AE, Dunivan G, Goode PS, Lukacz ES, Markland AD, Matthews CA, et al. Epidemiology, pathophysiology, and classification of fecal incontinence: state of the science summary for the National Institute of Diabetes and Digestive and Kidney Diseases (NIDDK) workshop. Am J Gastroenterol. 2015;110(1):127-36.

8. Tannenbaum C, Gray M, Hoffstetter S, Cardozo L. Comorbidities associated with bladder dysfunction. Int J Clin Pract. 2013;67(2):105-13.

9. Matthews CA, Whitehead WE, Townsend MK, Grodstein F. Risk factors for urinary, fecal, or dual incontinence in the Nurses' Health Study. Obstet Gynecol. 2013;122(3):539-45.

10. Amaro JL, Macharelli CA, Yamamoto H, Kawano PR, Padovani CR, Agostinho AD. Prevalence and risk factors for urinary and fecal incontinence in Brazilian women. Int Braz J Urol. 2009;35(5):592-8.

11. Yuaso DR, Santos JLF, Castro RA, Duarte YAO, Girão MJBC, Berghmans B, et al. Female double incontinence: prevalence, incidence, and risk factors from the SABE (Health, Wellbeing and Aging) study. Int Urogynecol J. 2018;29(2):265-72.

12. Brown HW, Wexner SD, Segall MM, Brezoczky KL, Lukacz ES. Quality of life impact in women with accidental bowel leakage. Int J Clin Pract. 2012;66(11):1109-16

13. Meyer I, Richter HE. Impact of fecal incontinence and its treatment on quality of life in women. Womens Health. 2015;11(2):225-38.

14. Tamanini JTN, D’Ancona CL, Botega, NJ, Rodrigues Netto Jr. N. Validação do "King's Health Questionnaire" para o português em mulheres com incontinência urinária. Rev Saúde Pública. 2003;37(2):203-11.

15. Yusuf SA, Jorge JM, Habr-Gama A, Kiss DR, Gama Rodrigues J. Evaluation of quality of life in anal incontinence: validation of the questionnaire FIQL (Fecal Incontinence Quality of Life). Arq Gastroenterol. 2004;41:202-8.

16. Santos CRS, Santos VLCG. Prevalência da incontinência anal na população urbana de Pouso Alegre - Minas Gerais. Rev Esc Enferm USP. 2011;45(1):180-6
17. Haylen BT, Maher CF, Barber MD, Camargo S, Dandolu V, Digesu A, et al. An International Urogynecological Association (IUGA) / International Continence Society (ICS) joint report on the terminology for female pelvic organ prolapse (POP). Int Urogynecol J. 2016;27(2):165-94.

18. Nascimento RCRMD, Álvares J, Guerra Junior AA, Gomes IC, Silveira MR, Costa EA, et al. Polypharmacy: a challenge for the primary health care of the Brazilian Unified Health System. Rev Saúde Pública. 2017;51(suppl 2):1-12.

19. Medeiros SM, Silva LSR, Carneiro JA, Ramos GCF, Barbosa ATF, Caldeira AP. Fatores associados à autopercepção negativa da saúde entre idosos não institucionalizados de Montes Claros, Brasil. Ciênc Saúde Colet. 2016;21(11):3377-86.

20. Faria CA, Benayon PC, Ferreira ALV. Prevalência de incontinências anal e dupla em idosas e impacto na qualidade de vida. Arq Ciênc Saúde. 2018;25(1):41-5.

21. Wu JM, Matthews CA, Vaughan CP, Markland AD. Urinary, fecal, and dual incontinence in older U.S. Adults. J Am Geriatr Soc. 2015;63(5):947-53.

22. Camtosun A, Sen I, Onaran M, Aksakal N, Özgür Tan M, Bozkirli I. An evaluation of fecal incontinence in women with urinary incontinence. Eur Rev Med Pharmacol Sci. 2016;20(10):1918-22.

23. Manonai J, Wattanayingcharoenchai R, Sarit-Apirak S, Vannatim N, Chittacharoen A. Prevalence and risk factors of anorectal dysfunction in women with urinary incontinence. Arch Gynecol Obstet. 2010;281(6):1003-7.

24. Markland AD, Richter HE, Kenton KS, Wai C, Nager CW, Kraus SR, et al. Urinary Incontinence Treatment Network. Associated factors and the impact of fecal incontinence in women with urge urinary incontinence: from the Urinary Incontinence Treatment Network's Behavior Enhances Drug Reduction of Incontinence study. Am J Obstet Gynecol. 2009;200(4):424-34.

25. Portella PM, Feldner Jr PC, Conceição JC, Castro RA, Sartori MG, Girão MJ. Prevalence of and quality of life related to anal incontinence in women with urinary incontinence and pelvic organ prolapse. Eur J Obstet Gynecol Reprod Biol. 2012;160(2):228-31.

26. Reigota RB, Pedro AO, de Souza SM, Costa-Paiva L, Pinto-Neto AM. Prevalence of urinary incontinence and its association with multimorbidity in women aged 50 years or older: a population-based study. Neurourol Urodyn. 2016;35(1):62-8.

27. Al-Safi ZA, Polotsky AJ. Obesity and menopause. Best Pract Res Clin Obstet Gynaecol. 2015;29(4):548-53. 
28. Torres KD, Rosa ML, Moscavitch SD. Gender and obesity interaction in quality of life in adults assisted by family doctor program in Niterói, Brazil. Ciênc Saúde Colet. 2016;21(5):1617-24.

29. Corica F, Bianchi G, Corsonello A, Mazzella $\mathrm{N}$, Lattanzio F, Marchesini G. Obesity in the context of aging: quality of life considerations. Pharmacoeconomics. 2015;33(7):655-72.

30. Yang Y, Herting JR, Choi J. Obesity, metabolic abnormality, and health-related quality of life by gender: a cross-sectional study in Korean adults. Qual Life Res. 2016;25(6):1537-48.

31. de Sam Lazaro S, Nardos R, Caughey AB. Obesity and pelvic floor dysfunction: battling the bulge. Obstet Gynecol Surv. 2016;71(2):114-25.
32. Andy UU, Harvie HS, Pahwa AP, Markland A, Arya LA. The relationship between fecal incontinence, constipation and defecatory symptoms in women with pelvic floor disorders. Neurourol Urodyn. 2017;36(2):495-98.

33. Mustain WC. Functional disorders: Rectocele. Clin Colon Rectal Surg. 2017;30(1):63-75.

34. Ditah I, Devaki P, Luma HN, Ditah C, NjeiB, Jaiyeoba C, et al. Neurourol Urodyn, 2005-2010. Clin Gastroenterol Hepatol. 2014;12(4):636-43.

35. Menees SB, Almario CV, Spiegel BMR, Chey WD. Prevalence of and Factors Associated With Fecal Incontinence: results from a population-Based Survey. Gastroenterology. 2018;154(6):1672-81. 